\title{
Modeling of Photovoltaic array in MATLAB
}

\author{
Hinaxi Patel ${ }^{1}$, Kedar Patil ${ }^{2}$ \\ Assistant Professor, Dept. of EE, Parul Institute of Technology College, Vadodara, Gujarat, India ${ }^{1}$ \\ Lecturer, Bhailalbhai \& Bhikhabhai Institute of Technology, Vallabh Vidyanagar, Gujarat, India ${ }^{2}$
}

\begin{abstract}
In this paper modeling of Photovoltaic array is done using circuit model in matlab.The single diode model is used in this paper. The procedure of finding unknown parameters of Photovoltaic array from data sheet is well explained. The iteration is listed in this paper which may helpful to verify the result with experimental data given by manufacturer data. By using only three points: open circuit, short circuit and maximum power point, the I-V (current voltage) characteristic is plotted. The atmospheric condition and effect of these conditions is clearly shown in I-V (current voltage) as well as $\mathrm{P}-\mathrm{V}$ (power voltage) characteristics.
\end{abstract}

Keywords: Open circuit voltage, short circuit current, maximum power point.

\section{I.INTRODUCTION}

Nowadays fossil fuels are widely used for producing electricity but they will be not available longer. By using this fossil fuels the problem of global warming is arised.To overcome this problem alternatives are found. Among them solar energy is one of the alternative. The main advantages of this alternative is available at free cost and do not pollute the atmosphere. The Photovoltaic system can generate direct current electricity without environmental impact and contamination when is exposed to solar radiation. Being a semiconductor device, the PV system is static, quite, and free of moving parts, and these make it have little operation and maintenance costs [2].In this paper single diode circuit model is analysed because it gives better understanding to electrical engineer and its behaviour is easily observed compare to complex equation. Accurate results are obtained using the singlediode model with a relative error of $0.37 \%$ compared to the double diode and three diode models [4]. For plotting PV cell characteristics parameters are found at three points: open circuit, short circuit and maximum power point. There are different type of $\mathrm{P}-\mathrm{V}$ cells are available in the market.As per the requirement and economic application wise they are chosen. Three types of solar cells: Copper indium deselinide thin film, multi crystal silicon and mono crystalline silicon cells and their I-V and P-Characteristics is well plotted and explained [2]. The role of Photovoltaic system is observed during critical load on distribution grid. The Photovoltaic system supplies uninterrupted supply to the critical load when there is fault in distribution grid and distribution grid cannot supply the power[3].By using manufacturer data sheet the simulated result is compared with experimental result .The accuracy of simulation model is higher and results are very close to the actual data given.

\section{II.WORKING OF PHOTOVOLTAIC CELL}

The solar cell is work on photovoltaic effect. The solar cell is p-n junction diode. When light shines on a solar cell, a large number of electron -hole pairs are created .Because of asymmetry in the P-N junction, the generated electrons tends to flow from $\mathrm{P}$-side to $\mathrm{N}$-side and the holes from $\mathrm{N}$-side to P-side, there is separation of charge carriers which can flow in external circuit is connected and current can flow in that circuit.[Fig.4].This separation of carriers are dependent on type of semi conductor material and on wave length of incident light.[8].

\section{EQUIVALENT CIRCUIT DIAGRAM}

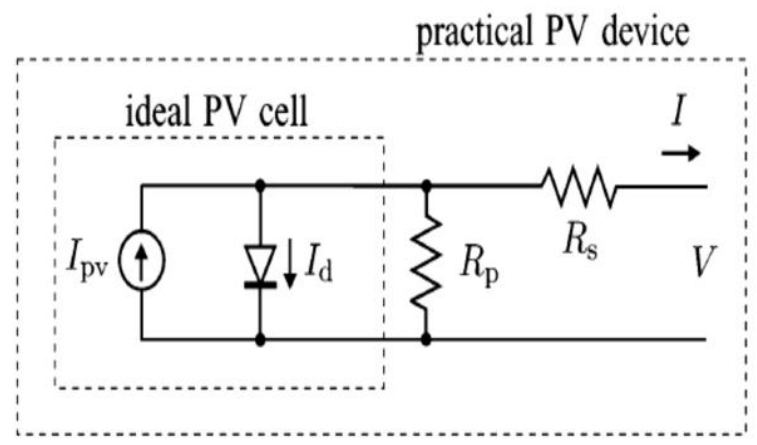

Fig.1 Single diode model of PV cell and practical PV device including $R_{S}$ and $\mathrm{R}_{\mathrm{P}}$

As shown in fig. 1 ideal PV cell not consisting of the series and parallel resistance but in practically they consisting of series and parallel resistance. This equivalent circuit of a PV cell has mainly four components: a light-induced current source, a diode parallel to the source, a series resistor and a shunt resistor. The light induced current is due to the separation and drift of the photon-generated electron whole pairs under the influence of the built-in field [9].

The basic ideal equation for V-I characteristic is

$I=I_{P V}$, cell $-I_{0}$, cell $\left[\exp \left(\frac{q V}{a K T}\right)-1\right]$

Practically arrays are composed of series and parallel connected PV cell and I-V characteristic of PV array is formed by following equation in which additional parameters like Series and parallel resistance is considered

$I=I_{P V}-I_{0}\left[\exp \left(\frac{V+I R_{S}}{V_{t} a}\right)-1\right]-\left(\frac{V+I R_{S}}{R_{P}}\right)$

This equation is useful for getting I-V characteristic at three remarkable points: Open circuit voltage $\left(\mathrm{V}_{\text {oc }}\right)$,short- 
circuit current $\left(\mathrm{I}_{\mathrm{sc}}\right)$ and at maximum power point(MPP) which is shown in fig. 2

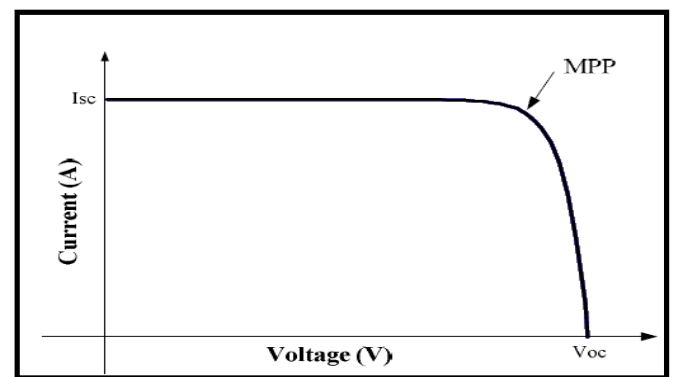

Fig.2 I-V characteristics at three important points: at maximum power point, open circuit voltage and short circuit current.

In single diode model, five points are needed to find the unknown parameters. For the two-diode model, seven points are extracted; and for the three diode model, nine points are required. Among all model single diode model gives accurate result [5].

For plotting I-V characteristic different parameters are required like series resistance, parallel resistance, ideality factor, diode saturation current. Manufacturer only give some parameters value like open circuit voltage $\left(\mathrm{V}_{\mathrm{oc}}\right)$, short circuit current $\left(\mathrm{I}_{\mathrm{sc}}\right)$, voltage at maximum power point $\left(\mathrm{V}_{\mathrm{mpp}}\right)$, current at maximum power point $\left(\mathrm{I}_{\mathrm{mpp}}\right)$, open circuit voltage/temperature coefficient $\left(\mathrm{K}_{\mathrm{v}}\right)$, short circuit current /temperature coefficient $\left(\mathrm{K}_{\mathrm{I}}\right)$. The one method for finding these unknown parameters are illustrated in this paper. Equation (2) can be written for the three key-points of the V-I characteristic: the short-circuit point, the maximum power point, and the open-circuit point.

\section{PARAMETER EXTRACTION}

The $I-V$ characteristic of the PV device shown in Fig. 2 depends on the internal characteristics of the device $R_{S}, R_{P}$ and on external influences such as irradiation level and temperature. The amount of incident light directly affects the generation of charge carriers, and consequently, the current generated by the device. The light-generated current $I_{P V}$ of the elementary cells, without the influence of the series and parallel resistances, is difficult to determine. Data sheets only inform the nominal short circuit current $\left(I_{S C, n}\right)$, which is the maximum current available at the terminals of the practical device. The assumption $I_{S C} \approx I_{P V}$ is generally used in the modeling of PV devices because in practical devices the series resistance is low and the parallel resistance is high. The light-generated current of the PV cell depends linearly on the solar irradiation and is also influenced by the temperature according to the following equation:

The light generated current of Photovoltaic cell is depends linearly on solar radiation:

$I_{p v}=\left(I_{p v, n}+K_{I} \Delta \mathrm{T}\right) \frac{G}{G_{n}}$

Where,

$\Delta T=T-T_{n}$

$T$ - Actual temperature or cell temperature in $\mathrm{K}$

$T_{n} \quad$ - Nominal temperature in $\mathrm{K}$
$G$ - Solar irradiation in $\mathrm{W} / \mathrm{m}^{2}$

$G_{n} \quad$ - Solar nominal irradiation nominal $\mathrm{W} / \mathrm{m}^{2}$

Diode saturation current expressed by

$I_{o}=I_{o, n}\left(\frac{T_{n}}{T}\right)^{3} \exp \left[\frac{q E_{g}}{a k}\left(\frac{1}{T_{n}}-\frac{1}{T}\right)\right]$

Where, $E_{g} \quad$ Band gap energy of semiconductor in $\mathrm{eV}$ (For polycrystalline $\mathrm{Si}, E_{g}=1.12 \mathrm{eV}$ )

The saturation current $\mathrm{I}_{0}$ of the $\mathrm{PV}$ cells that compose the device depend on the saturation current density of the semiconductor $\left(\mathrm{J}_{0}\right.$, generally given in $\left[\mathrm{A} / \mathrm{cm}^{2}\right]$ and on the effective area of the cells. The current density $J_{0}$ depends on the intrinsic characteristics of the PV cell, which depend on several physical parameters such as the coefficient of diffusion of electrons in the semiconductor, the lifetime of minority carriers, the intrinsic carrier density, etc.The value of the diode constant a may be arbitrarily chosen. Usually, $1 \leqslant \mathrm{a} \leqslant$ 1.5 and the choice depend on other parameters of the $I-V$ model. The value of a can be later modified in order to improve the model fitting, if necessary. This constant affects the curvature of the curve $I-V$ and varying a can slightly improves the model accuracy [8].

Diode saturation current at nominal temperature is expressed by

$I_{o, n}=\frac{I_{s c, n}}{\exp \left(\frac{V_{o c, n}}{a V_{t, n}}\right)-1}$

For improving the model equation (5) is replaced by

$I_{o}=\frac{I_{s c, n}+K_{I} \Delta T}{\exp \left(\frac{V_{o c, n}+K_{V} \Delta T}{a V_{t}}\right)-1}$

The relation between $R_{s}$ and $R_{p}$, the only unknowns of (2), may be found by making $P_{\max , m}=P_{\max , e}$ and solving theresulting equation for $R_{S}$, as shown.

$$
\begin{aligned}
& P_{\text {max }, m}=V_{m p}\left\{I_{p v}-I_{0}\left[\exp \frac{q}{k T}\left(\frac{V_{m p}+R_{S} I_{m p}}{a N_{S}}\right)-1\right]\right. \\
& \left.\quad-\left(\frac{V_{m p}+R_{s} I_{m p}}{R_{p}}\right)\right\} \\
& =P_{\text {max }, e} \\
& R_{p} \\
& =\frac{V_{m p}+I_{m p} R_{s}}{V_{m p} I_{p v}-V_{m p} I_{0} \exp \left[\left(\frac{V_{m p}+R_{S} I_{m p}}{a N_{S}}\right) \frac{q}{k T}\right]+V_{m p} I_{0}-P_{\text {max }, e}}
\end{aligned}
$$

Each iteration updates $R_{S}$ and $R_{\mathrm{p}}$ toward the best model solution, so (9) may be introduced in the model.Initially $R_{s}$ and $R_{\mathrm{p}}$ are assumed but after each iteration there is some value of $R_{s}$ and $R_{\mathrm{p}}$ and hence light generated current is found by following expression:

$I_{\mathrm{pv}, \mathrm{n}}=\frac{R_{\mathrm{p}}+R_{s}}{R_{\mathrm{p}}} I_{\mathrm{sc}, \mathrm{n}}$

The initial value of $R_{s}$ is zero and the initial value of $R_{\mathrm{p}}$ is found by,

$$
R_{p, \text { min }}=\frac{V_{m p}}{I_{s c, n}-I_{m p}}-\frac{V_{o c, n-} V_{m p}}{I_{m p}}
$$




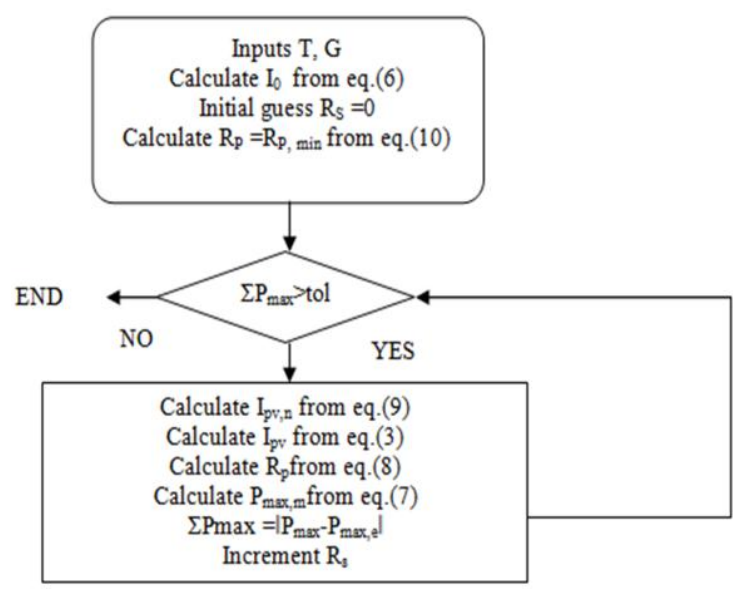

Fig.4 Flowchart for determine of the photovoltaic panel parameters

From the above flow chart we can find unknown parameters of PV panel $R_{S}$ and $R_{P}$.We are assuming diode ideality facor is previously assumed here.

\section{Parameters calculation for photovoltaic array}

Data sheet for photovoltaic array at $25^{\circ} \mathrm{C}, 1.5 \mathrm{AM}$, $1000 \mathrm{~W} / \mathrm{m}^{2}$ (KC200GT)

\begin{tabular}{|l|l|}
\hline Imp - Current at maximum power & $3.16 \mathrm{~A}$ \\
\hline Vmp -Voltage at maximum power & $17.4 \mathrm{~V}$ \\
\hline Pmax,e-Max power & $55 \mathrm{~W}$ \\
\hline Isc-Short circuit current & $3.45 \mathrm{~A}$ \\
\hline Voc-Open circuit voltage & $21.7 \mathrm{~V}$ \\
\hline Kv-Voltage co-efficient & $-0.076 \mathrm{~V} / \mathrm{K}$ \\
\hline $\begin{array}{l}\text { KI- Short circuit temperature co- } \\
\text { efficient }\end{array}$ & $0.0014 \mathrm{~A} / \mathrm{K}$ \\
\hline Ns-Number of series connected cell & 36 \\
\hline a=Ideality factor & 1.3 \\
\hline
\end{tabular}

Table:1 Data sheet for photovoltaic array at $25^{\circ} \mathrm{C}$, $1.5 \mathrm{AM}, 1000 \mathrm{~W} / \mathrm{m}^{2}$ (SHELL SM 55)

\begin{tabular}{|l|l|l|l|}
\hline & $\mathrm{Rs}$ & $\mathrm{Rp}$ & $\mathrm{Pmax}$ \\
\hline Iteration 1 & 0 & 77.59 & 54.88 \\
\hline Iteration 2 & 0.100 & 89.34 & 55.00 \\
\hline Iteration 3 & 0.150 & 96.38 & 54.98 \\
\hline Iteration 4 & 0.160 & 98.28 & 55.00 \\
\hline
\end{tabular}

Table 2 Calculated Parameters for photovoltaic array (SHELL SM 55) at each iteration

\section{RESULTS AND DISCUSSION}

The light-generated current of the PV cell depends linearly on the solar irradiation:

$$
I_{P V}=\left(I_{P V, n}+K_{I} \Delta T\right) \frac{G}{G_{n}}
$$

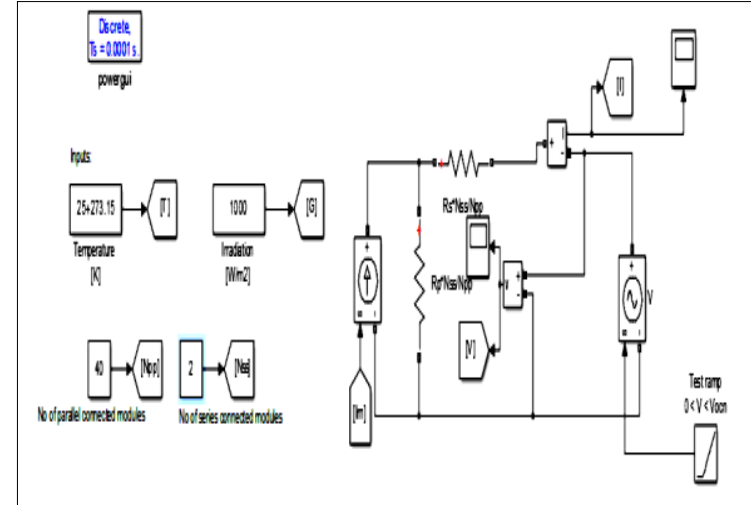

Fig. 5 Circuit model for photovoltaic array

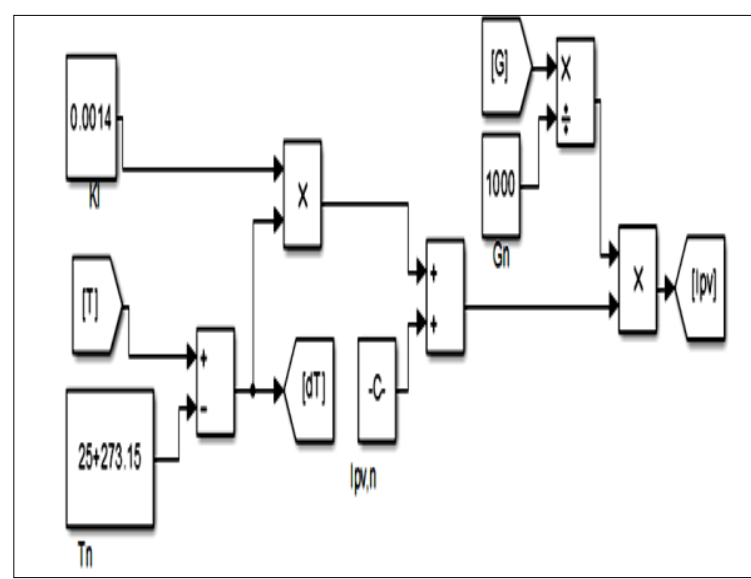

Fig. 5.1Modeling of light generated/photon current

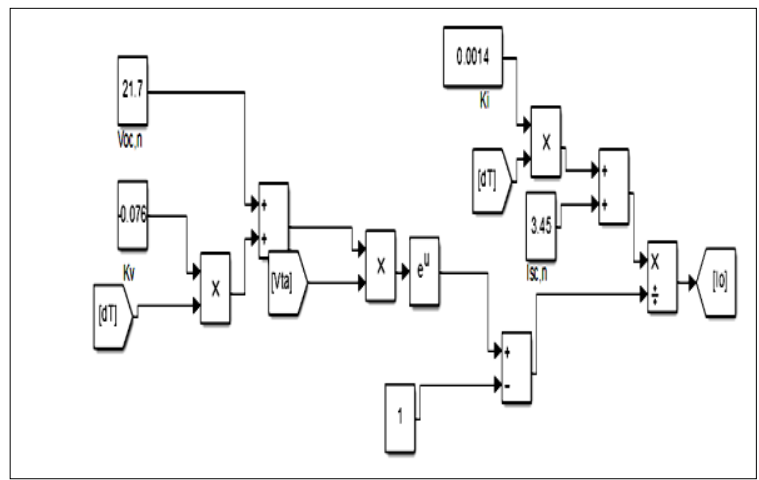

Fig. 5.2Modeling of reverse saturation current

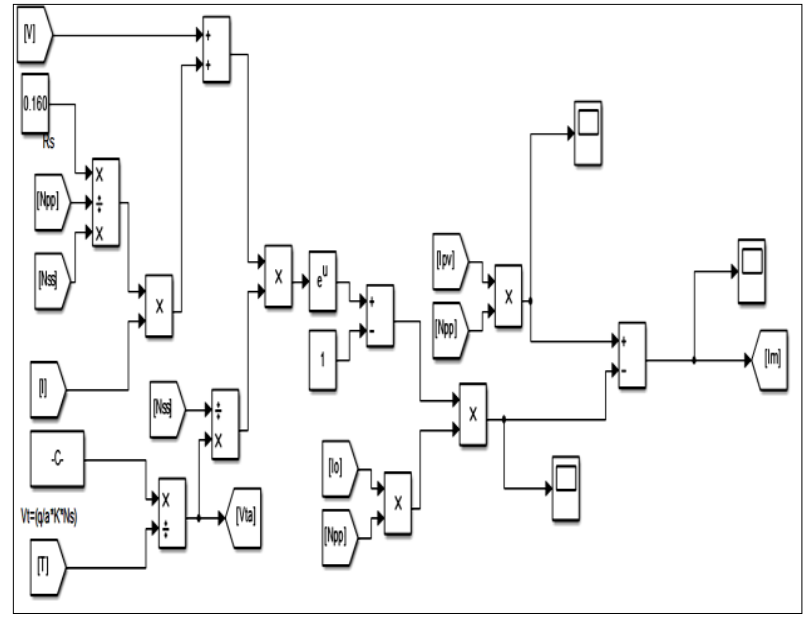

Fig. 5.3 Modeling of Photovoltaic current 
Diode saturation current:

$$
I_{0}=\frac{I_{s c, n}+K_{I} \Delta T}{\exp \left(\frac{V_{o c, n}+K_{V} \Delta T}{a V_{t}}\right)-1}
$$

Photovoltaic current

$$
I_{m}=N_{P P} I_{p v}-N_{P P} I_{0}\left[\exp \left(\frac{V+I R_{s} \frac{N_{S S}}{N_{P P}}}{V_{t} a}\right)-1\right]
$$

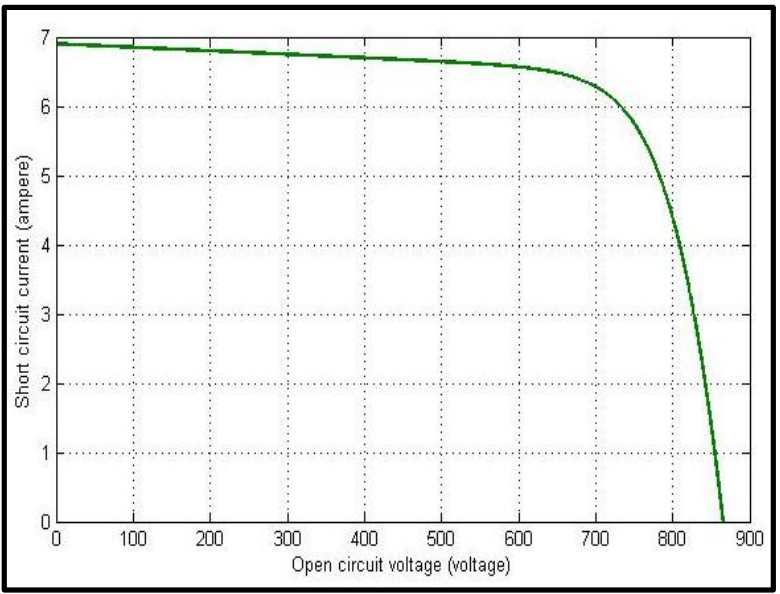

Fig. 5.5 I-V Characteristics of PV module in Standard test condition (Data taken from SHELL SM 55 datasheet)

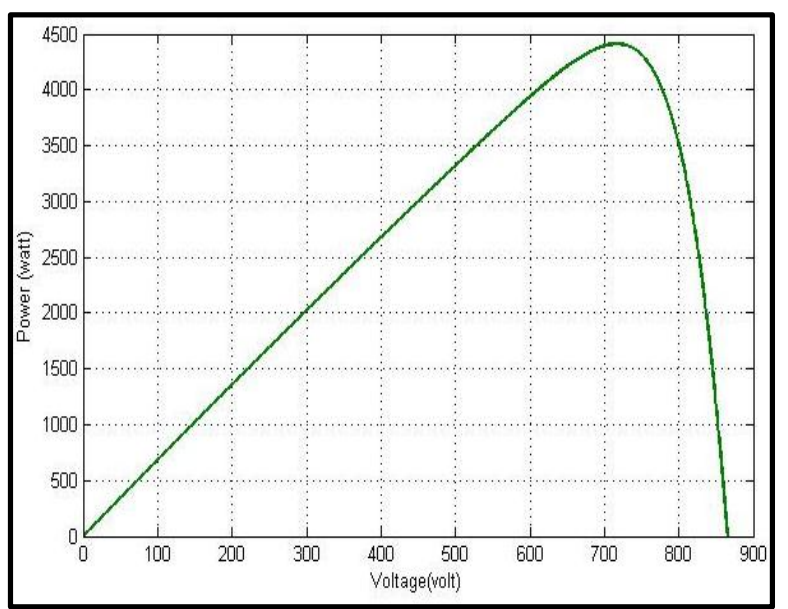

Fig. 5.6 P-V Characteristics of PV module in Standard test condition (Data taken from SHELL SM 55 datasheet)

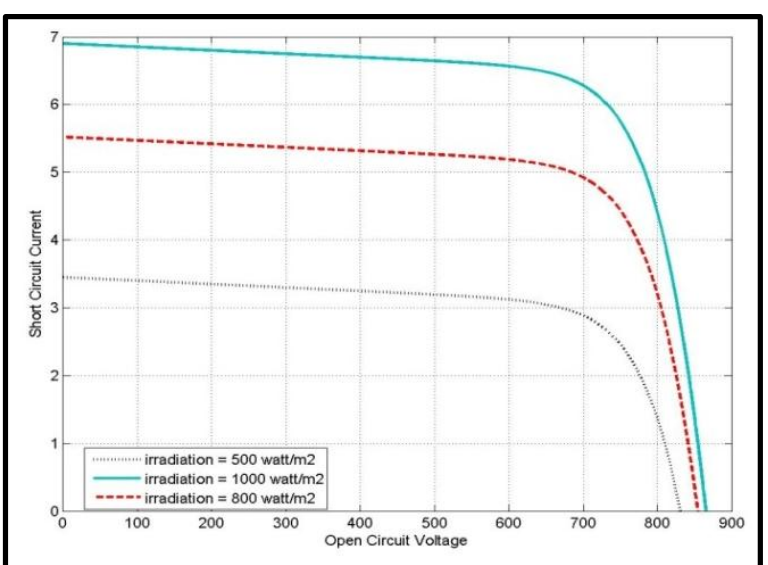

Fig.5.7 I-V characteristic at different irradiation(Data taken from SHELL SM 55 datasheet)

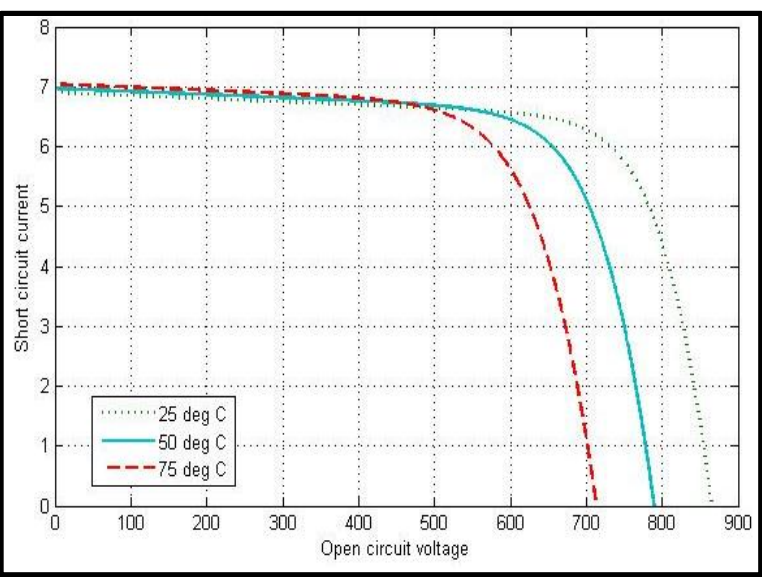

Fig.5.8 I-V characteristic at different temperature and at $1000 \mathrm{~W} / \mathrm{m}^{2}$ (Data taken from SHELL SM 55 datasheet)

\section{CONCLUSION}

By using characteristic equations of photovoltaic array, current and voltage characteristic are plotted. The simulation result is exactly match with datasheet. The I-V characteristic and P-V characteristic is plotted in fig.5.5 and 5.6 respectively. During atmospheric changing condition the I-V characteristic of photovoltaic array is changed. As the irradiation increase the current of photovoltaic array is an increase which is shown in fig.5.7 and as the temperature increase the photovoltaic voltage is decrease which is observed in fig.5.8.From these figures we conclude that photovoltaic array current is directly proportion to the irradiation and voltage is inversely proportional to the temperature. The same result we can plot for other datasheet values. The main purpose by adopting second method, we can find unknown parameters $R_{s}$ and $R_{\mathrm{p}}$ of PV panel from any given datasheet .Please note that here diode ideality factor a is assumed.

\section{REFERENCES}

[1] Huan-Liang Tsai, Ci-Siang Tu, and Yi-Jie Su, "Development of Generalized Photovoltaic Model Using MATLAB/SIMULINK", Proceedings of the World Congress on Engineering and Computer Science 2008, WCECS 2008, October 22 - 24, 2008.

[2] Weidong Xiao, William G. Dunford, Antoine Capel, "A Novel Modeling Method for Photovoltaic Cells", IEEE Power Electronics Specialists Conference, 2004

[3] Dezso Sera, Remus Teodorescu, Pedro Rodriguez, "PV panel model based on datasheet values", IEEE, 2007.

[4] Soliman A. Mahmoud, Mejd M. Alsari, EsraI. Reda,Ruqiya M. Alhammadi, "MATLAB Modeling and Simulation of Photovoltaic Modules", IEEE, 2012

[5] Roberto Faranda, Sonia Leva, "Energy comparison of MPPT techniques for PV Systems", WSEAS Transaction on Power System, Vol.3, June 2008

[6] IEEE Std 1562-2007-IEEE Guide for Array and Battery Sizing in Stand-Alone Photovoltaic Systems

[7] Marcelo Gradella Villalva, Jonas Rafael Gazoli, Ernesto Ruppert Filho, "Comprehensive Approach to Modeling and Simulation of Photovoltaic Arrays", IEEE Transaction on Power Electronics, Vol. 24, No. 5, May 2009.

[8] M. G. Villalva, J. R. Gazoli,E. Ruppert F, "Comprehensive approach to modeling and simulation of Photovoltaic arrays", IEEE Transactions on Power Electronics, 2009 vol. 25, no. 5, pp. 1198-1208, ISSN 0885

[9] N. Pongratananukul, T. Kasparis, "Tool for Automated Simulation of Solar Arrays Using General-Purpose Simulators", IEEE, 2004.

[10] Shell SM55 Photovoltaic Solar Module data sheet. 